\title{
Energy and resource saving technologies of building materials production using solar energy
}

\begin{abstract}
The article deals with the production of building materials as an important sector of the country's economy. This sector of the economy is characterized by a high level of material intensity. The problem of finding new sources of energy is the most important thing in the world. The use of solar energy for heat treatment of various concretes is a new energyefficient promising direction, developed by scientists of Korkyt Ata Kyzylorda state University. The use of solar technology makes it possible to save $50-100 \%$ of traditional fuels with an environmentally friendly environment, without emissions from fuel combustion, high quality and low cost of concrete products and structures. All developed technologies of the university are aimed at reducing the impact on the environment, energyand resource saving and achieving a high level of quality for life for the population. As a whole, the scientists of the Korkyt Ata Kyzylorda state University see the formula for the development of science in the new decade sustainable development of Kazakhstan in the future.
\end{abstract}

Keywords: energy efficiency, resource saving, solar energy, concrete, arbolite, foam concrete, temperature, humidity
Volume 3 Issue 3 - 2017

\author{
Aruova LB,' Bissenov KA, ${ }^{2}$ Dauzhanov $\mathrm{NT}^{3}$ \\ 'Doctor of Technical Sciences, professor, Korkyt Ata Kyzylorda \\ State University, Kazakhstan \\ ${ }^{2}$ Doctor of Technical Sciences, Korkyt Ata Kyzylorda State \\ University, Kazakhstan \\ ${ }^{3}$ Associate Professor, Korkyt Ata Kyzylorda State University, \\ Kazakhstan
}

Correspondence: Aruova LB, Doctor of technical sciences, Professor, Korkyt Ata Kyzylorda state University, 29A Aiteke Bi Street, Kazakhstan, Email ecoeducation@mail.ru

Received: May 03, 2017 | Published: August 23, 2017

\section{Introduction}

The problem of rational use of energy resources is becoming increasingly important all over the world and its solution becomes a strategic task for many states. The continued global economic crisis, the steady rise in prices for natural energy resources, environmental issues, reducing emissions of harmful substances and greenhouse gases into the atmosphere cause the need to take immediate comprehensive measures to solve the issues of energy conservation and energy efficiency. ${ }^{1}$ The manufacturing industry has an increasing impact on the formation of the middle class. Thus, according to the Information Technology and Innovation Fund (USA), the creation of 1 workplace in the manufacturing industry leads to the creation of 2 to 5 additional jobs in other sectors, the development of technology leads to an increase of knowledge and skills of workers; in the USA, the level of wages in manufacturing industry is $9 \%$ higher on average than in other sectors of the economy; sectors of manufacturing industry - the most innovative in the economy, in the US $70 \%$ of research and development work is done on this sector; the state of the manufacturing industry and the service sector are interdependent (for example, services based on information and communication technologies highly depend on manufactured goods). State program of industrial and innovative development of the Republic of Kazakhstan for 2015-2019.

The production of building materials is an important sector of the country's economy, has a developed structure and meets the needs of internal construction considerably. At the same time, this sector is characterized by a large consumption of energy resources, production costs and a high level of material intensity. The specific weight of imported raw materials being used, materials, purchased products, fuel in the costs of production remains high. The main objective of building materials production is complete providing the domestic market with building materials of domestic production and increasing the export potential. One of the main directions of technological development is the creation of new industries: modern building materials and constructions with increased (by 15-20 percent) physical and mechanical properties for the erection of buildings and structures; heat insulating materials based on mineral and polymeric raw materials, ash and slag wastes; light polystyrene concrete; cellular glass.

Modernization of existing construction industries today requires: the development and implementation of technologies for obtaining building materials with high technological and operational parameters using their own raw materials to ensure deeper processing of raw materials and materials, increasing the involvement of secondary resources in production; development and implementation of resource-saving technologies for the production of efficient building materials and products; re-equipment of cement plants by introducing three new production lines for dry cement production, which will reduce its energy intensity by 20-30 percent, use alternative fuels for firing clinker; mastering of technologies for the production of ceramic products; modernization of existing production of non-metallic materials; introduction of technologies related to the organization of production of energy-saving, laminated, mirror glass, bent tempered glass into the glass production, which will reduce the import of these products. The problem of finding new sources of energy is one of the most important, because it depends on the further development of all industries in all countries of the world. In order to reduce energy intensity, material intensity, construction industry cost, it is necessary to involve innovative technologies actively, including using renewable 
energy sources. Hydrocarbon sources - oil and gas are irreplaceable and probably at the end of this century their reserves on Earth will run out. Using solar energy is one of the simplest and inexpensive. In many technologically advanced countries, intensive research is held and this type of energy in Europe has already been used for heating and lighting residential and social buildings. In Kazakhstan and Russia, such research on using solar energy is widely conducted in the industrial and civil spheres and, especially in the construction industry, in particular in the precast concrete industry and others. The use of solar energy for heat treatment of reinforced concrete products required extensive theoretical and experimental research. In the Soviet Union the issue was carefully studied by scientists of Russia and Kazakhstan and a technology for using methods of direct use of solar energy was proposed for the production of precast products at grounds. These studies covered a wide range of issues-theoretical, experimental, technological, ecological and economic. As a result, various methods of solar technology were developed and introduced into production in the southern regions of the country. The studies on using solar energy are carrying out in Korkyt Ata Kyzylorda State University. The scientists are solving the problems using solar technology for the production of precast reinforced concrete products at plant sites not only seasonally during the warm period of the year, but also in the cold season, i.e. all year round, ${ }^{2-5}$ as well as the tasks on the application of solar technology not only for conventional concrete, but also for materials such as arbolite, polystyrene concrete, foam concrete, etc. ${ }^{6-10}$

The extensive research has begun with the development of theoretical issues. One of the first objectives was the problem of heat exchange of manufactured products with the environment. Heat transfer during the heating of concrete occurs through the sides of the mold and takes place at an early stage with an increase in the temperature of the concrete from the sides of the mold facing the sun. As concrete is heated, the temperature fields undergo certain changes and heat exchange occurs in the movement of heat from the concrete to the outside. When the molded articles are held in film chambers, heat transfer takes place outside before the concrete reaches maximum temperature; the same takes place during cooling. The calculations showed that heat exchange with the medium during the heating process is of no decisive importance when heat treatment of concrete in the summer. In cold months or in rainy cloudy weather, when the difference in temperatures of ambient air and concrete is very noticeable, this process is of great importance. In this case, it is necessary either to extend the time of keeping the concrete in the mold or to use a duplicate source of warming up. The study of heat transfer issues made it possible to develop a technology for heat treatment of products.

An important issue for ensuring YHE conditions for hardening concrete, and therefore for the quality of the concrete structures being manufactured is the humidity of the medium

Usually due to mass exchange with the environment and internal mass transfer, concrete quickly loses moisture upon hardening, which leads to a lack of strength. This is especially evident when the molded products are kept in a dry, hot climate. The performed researches made it possible to find a simple but effective solution - covering the surface of products in the form by installing a special translucent, but heat-insulating coating on it. Due to this coating, a moisture content of $100 \%$ is formed in the gap $2-2.5 \mathrm{~cm}$ between the concrete surface and the coating. This creates a comfortable environment for hardening concrete and ensuring the production of high quality products. Manufactured with such a coating of reinforced concrete products have high strength characteristics and durability. ${ }^{11-13}$ High quality of concrete, its structure and properties have been determined by longterm research carried out in Kyzylorda state university and factory precast concrete factories in Aktau, Kyzylorda cities. In all cases, the structure and properties of concrete (compressive strength, tensile strength, module of elasticity, frost resistance) did not differ only from those of concretes hardened for 28 days in normal temperature and humidity conditions, but even exceeded them.

Based on theoretical principles and experimental studies, technologies were developed for the production of various concrete products at factory sites with heat treatment of solar energy products. ${ }^{12-14}$ The technology was constructed as follows. Prepared for the laying of concrete forms on the landfill were cleaned after the formwork of previously manufactured products and lubricated. They installed reinforcements with fasteners, which provide the protective layer of concrete that is set by the project. Concrete mixture is delivered to the ground from the concrete mixing plant in any way (vehicles, bunkers, auto concrete pumps, etc.), into a mold, compacted, the surface of the products is smoothed and immediately a molded product is placed on the molded product with a close fit to the sides of the mold. For more efficient use of solar energy, the molding of products should be started working at 8 a.m.so that the most powerful radiation flux from the Sun would give an opportunity to convey more heat to the concrete within a day, and, consequently, to ensure fast hardening of the concrete.

In the development of the technology, serious attention was paid to the determination of optimal modes of holding products to form. Studies have shown that for a day concrete acquires strength equal to $50-60 \%$ of the design, but on particularly hot days, strength in a day reaches $70-75 \%$. Hardened products are decompacted, stacked on a polygon in piles, covered with tarpaulins or polyethylene film and remain in this position for 24 hours, during which concrete achieves a strength of $70-80 \%$ of the design. When holding the products on the landfill, it is better to cover their stacks with a tarpaulin, which is recommended to be irrigated with water after 2-3 hours during the day. The studies have shown that the molded products are conveniently held in a light chamber made of polyethylene film. This chamber is pushed onto the stack and the products are kept in it as in a greenhouse, continuing to heat up from the sun's rays penetrating through the film. In the cold season, the molded products are stacked in a film chamber in which heat from TEN or infrared radiators are fed from above and below. Such additional heat supply to the solar radiation makes it possible to ensure, within 24 hours, the achievement of concrete strength up to $75-80 \%$ of the design. In this technology, the surface of concrete in products is covered with a film-forming liquid, which after 20-30 minutes. Solidifies in the form of an invisible film 100 microns thick and reliably protects concrete from moisture loss, Figures $1 \& 2$. For the additional heating of concrete in this case, 20 to $60 \mathrm{~kW}$ of electric power per $1 \mathrm{~m} 3$ of concrete is consumed, which is much less than for steam heating or electric heating. The products are decontaminated only when the temperature difference between the concrete surface and the ambient air is not more than $200 \mathrm{C}$. 


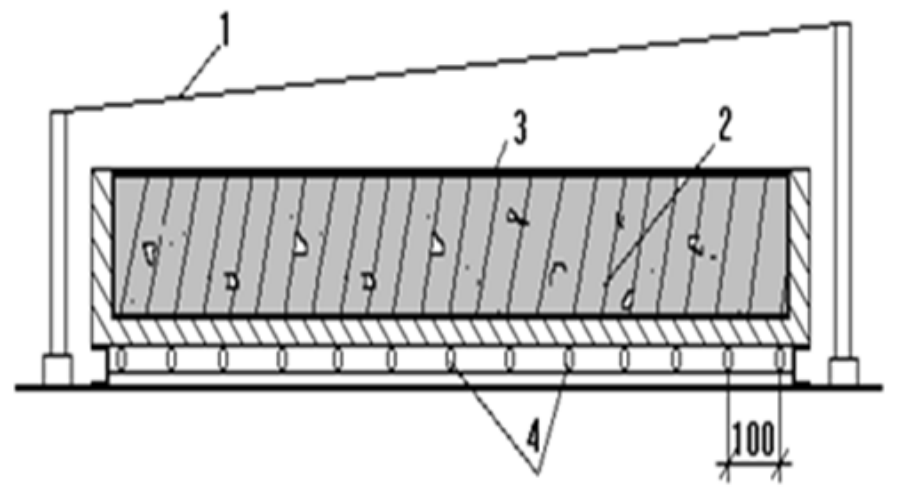

Figure I Scheme of intensification of concrete hardening by electric tubular heaters in a light-transparent chamber. (I) translucent coating, (2)freshly molded product, (3) film-forming composition, (4)electric tubular heaters.

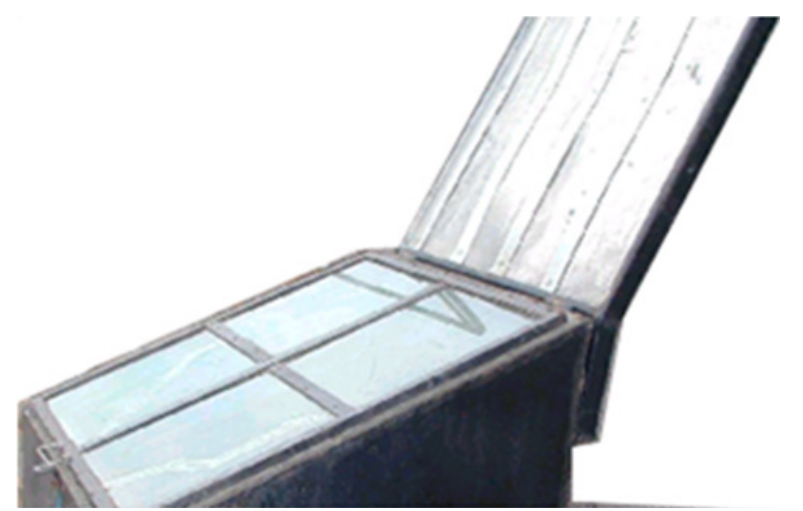

Figure 2 Heliochamber for heat treatment of concrete with a two-way supply of thermal energy of Kyzylorda city.

New approaches to the technology of solar thermal treatment of prefabricated reinforced concrete structures in dry hot climate of the Republic of Kazakhstan provide savings of $50-100 \%$ of traditional fuel, environmentally friendly environment, boiler houses which are free from smoke emissions, guaranteed high quality of products and structures at a lower cost with a daily cycle of turnaround forms. Kyzylorda State University developed a new highly effective method for combined heliothermal treatment of conventional concrete, polystyrene concrete, arbolite through heliosystems with a circulating intermediate heat carriers at landfills and in closed workshops. ${ }^{15}$ The method consists in obtaining high-quality concrete products and structures year-round, effectively using solar energy in the autumnspring and winter seasons of the year using year-round heliosystems with a circulating intermediate heat carrier, and also involving traditional types of energy in the absence of solar energy. Herewith heliochamber or helioform with the product under the heliocover pass (TT) thermal treatment in the summer seasons of the year under heliopoligon conditions, as well as in the autumn-spring-winter periods of the year, and in the absence of solar radiation a year-round helio-system with an intermediate hear carrier is connected.

Thermal solar treatment passes through soft modes at a maximum temperature of 700 degrees in the chamber or under the heliocover, with an increase in the rise temperature of 4-7 hours, conditional isothermal aging of the product for 6-7 hours, and cooling to $35^{\circ} \mathrm{C}$. $100 \%$ humidity is created in the chamber due to the fact that water is poured into the bottom of the chamber The strength of concrete is
$50-70 \%$ R28 at 24-hour age. This method of thermal solar processing of concrete products will give year-round heat treatment, the possibility of saving $50-100 \%$ of traditional fuels, environmentally friendly nature, high quality of manufactured products and structures. Thermal solar treatment $(\mathrm{TH})$ through a solar system with the use of an intermediate heat carrier was developed for polystyrene concrete ("Innovative patent for invention № 25072. The method of heat treatment of building products from polystyrene concrete mixture, Kazpatent, Innovative patent № 28207. The method of heat treatment of arbolitic building products. Kazpatent, Published 19.02.2014.), Figures $3-5 . \cdot^{16,17}$

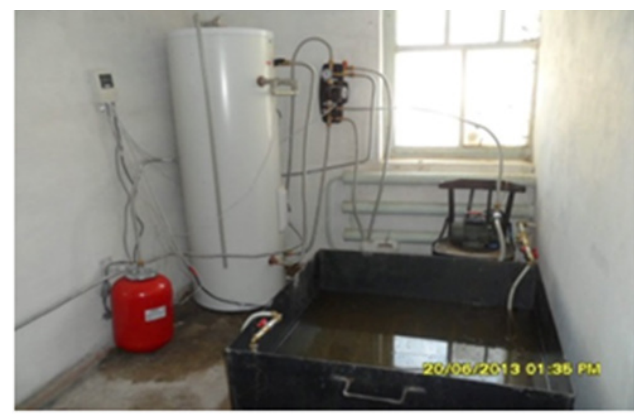

Figure 3 Heliosystem of heat treatment with intermediate coolant (boiler, electronic controller, pump). Pilot plant.

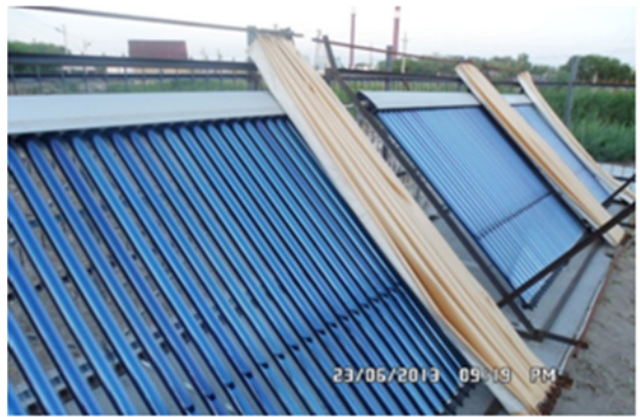

Figure 4 Heliosystem with a circulating intermediate coolant. Pilot plant.

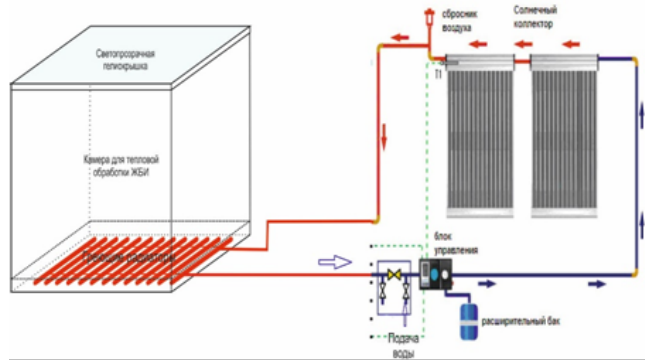

Figure 5 Heat treatment in a translucent in a in a heliochamber with duplication through a heliosystem with a circulating intermediate coolant and additional-duplicating types of energy.

In the world, about 600 million tons of rice husks are formed every year as a result of threshing. For the most part, it is burned in furnaces or subjected to a burial, requiring the attraction of large land. But the most interesting is that the husks do not dissolve in the ground due to the presence of silicon dioxide in it. Burning husks lead to the release of substances that can adversely affect the nature and health of a person. The utilization of rice husks is an urgent problem all over the world, especially in countries where rice is the main cereal product (China, India, Egypt, South Korea, Africa and 
partly Russia, Uzbekistan). Meanwhile, the utilized rice husks can be of great use to humans; its potential is still little used in industry. The University scientists have proved by their studies the possibility of obtaining a new composite material-arbolite based on rice husks, and also proposed an effective technology for thermal processing of arbolite using solar energy. As a result of the carried out researches for the thermal processing of the arbolite, the intensified heat treatment modes were not recommended. An attempt to steam the arbolite as ordinary concrete led to a decrease in strength. This is due to the fact that when steaming, internal stresses increase due to volumetric deformations of the aggregate, which disrupt the integrity of the material structure, while the release of sugars from wood aggregate increases, which contributes to the "poisoning" of concrete. The best results were obtained with low-temperature treatment of arbolite in soft modes: temperature $40-50^{\circ} \mathrm{C}$ and relative humidity $80 \%$. In this mode, the arbolite acquires a form-breaking strength after 18-20 hours. However, its strength does not exceed $25-40 \%$ of the branded, and the humidity remains within $30-35 \%$. To further improve strength and reduce humidity to regulated values, additional exposure of the products in a closed warehouse at $16-18^{\circ} \mathrm{C}$ for at least $7-14$ days is required. After that, the products can be sent to the warehouse with any temperature-humidity regime - natural storage, eliminating moisture. Hardening of the product is an important technological operation in the production of arbolite, that is why studying of hardening processes and choosing the best ways to accelerate them have a great practical importance. It was established that in all cases the thermal treatment of the arbolite at $40^{\circ} \mathrm{C}$ and relative air humidity of $50-60 \%$ is most effective. An increase in the heating temperature above $40^{\circ} \mathrm{C}$ leads to a decrease in the final strength of the material due to the deformative properties of wood and other cellulose-containing aggregates.

For products and structures made of arbolite, the heat treatment mode has to provide not only the required tempering and design strength, but also the release moisture in products not exceeding a predetermined value. To reduce the humidity of products and structures, their heat treatment must be carried out under conditions conducive to the evaporation of moisture from the arbolite. Such heating has to be carried out at a temperature of no more than $400 \mathrm{C}$ in the chambers equipped with thermoelectric coolers (TECs), heaters, infra-red radiators or gas burners, with additional ventilation in them. Heat treatment of arbolite products in saturated steam or steam-air environment, as well as on thermal pallets is not allowed. Today, the relevance obtains the solution of the question of heat treatment of almost all types of concretes, including light ones, using the unconventional energy-solar energy.

New methods of organizing solar thermal treatment technologies for various types of concrete products in a dry hot environment will make it possible to save $50-100 \%$ of traditional types of fuel environmentally friendly nature, without emissions from fuel combustion, high quality and low cost of concrete products and structures. The University has developed effective methods for combined helio-thermal treatment in translucent chambers under a film-forming composition using not only direct solar radiation but also with additional heating of helioforms through solar modules, Figure 6. Aruova LB, Dauzhanov NT, Bissenov KA, Krylov BA, Gussev BV (Patent "Heliochamber for heat treatment of concrete products". Kazpatent №31795 от 22.12.2016). ${ }^{18,19}$ The technology relates to the field of methods for year-round combined heat treatment of various types of concrete (reinforced concrete products, polystyrene concrete, arbolite, foam concrete) using translucent helio-covers, solar power plant system and duplicating energy sources. The method consists of an obtainment of a high-quality concrete products and structures year-round, making maximum use of solar energy in the autumnspring and winter seasons of the year using year-round solar power stations and duplicating electricity. A translucent helio-chamber or helioform with a helio-lid product undergoes heat treatment in the summer period under the conditions of the helio-polygon together with the solar power plant system, where in the autumn-springwinter periods of the year and in cloudy weather additional-doubling sources of energy are connected, in case of shortage or lack of solar energy. The main equipment for helio-thermal treatment is heliolid. The distance between the surface of freshly laid concrete and the translucent coating is $20-30 \mathrm{~mm}$. As a translucent material, it is recommended to use: a polyethylene uncoated stabilized film of SIC, CT, T grades 150-300 microns thick; Polyvinyl chloride plasticized technical film of grades C and B with a thickness of 150-230 $\mu$; glass with a thickness of 4-6 mm. When using a translucent coating in the autumn-winter-spring periods of the year with a combined solar thermal treatment, it is advisable to place the translucent heliocover at an angle to the horizon. The thermal treatment is carried out in soft modes at a maximum temperature of no more than 700 degrees in the chamber or under the heliocover, with a rise in temperature of 5-7 hours, a conditional isothermal holding time of 5-7 hours, and a slow cooling to $35-500 \mathrm{C}$. The moisture mode of hardening of products is created in the chamber by covering the products with a wet tarpaulin.

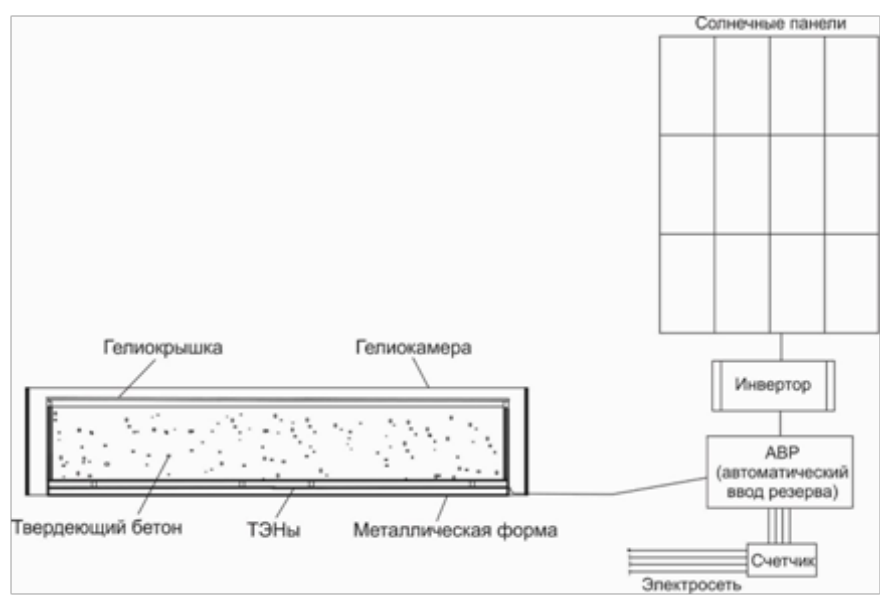

Figure 6 Heliosystem for the use of solar energy through solar modules for heat treatment of various types of concretes.

The established strengths of polystyrene-concrete samples that underwent heliothermal treatment showed that they exceed the strength of samples that solidified in normal medium by $40-100 \%$. Polystyrene concrete samples of medium density D800 reach a solar chamber with an intermediate coolant of $7.9 \mathrm{MPa}$, under normal conditions 5.5 MPa-higher by $69.6 \%$; Samples with an average density of D500 are reached in a solar chamber with an intermediate heat carrier of $3 \mathrm{MPa}$, under normal conditions of $1.1 \mathrm{MPa}-$ by $40 \%$ higher; Polystyrene concrete with an average density of D350 reaches in the solar chamber with an intermediate coolant of $2.8 \mathrm{MPa}$, under normal conditions of $0.9 \mathrm{MPa}$ it is higher by $32 \%$. Arbolite mark 15 on rice husk reaches when hardening in a solar chamber 1,61MPa. The investigated structures of polystyrene concretes, arbolites subjected to various methods of solar thermal treatment, showed that the phase chemical composition of the neoplasms is similar to the concrete stone formed under normal conditions, this proves once again their high quality. ${ }^{20-23}$ 
The performed researches give the grounds for a positive evaluation of the methods of solar technology and recommendations for a wide production use of helio-thermal treatment of various concrete products, Figures $7 \& 8$. Scientists have developed and tested new high-efficiency heliotechnologies for foam concrete. The lowenergy technology of production of foam concrete products by helium heating allows reducing energy costs for heat treatment, to receive high-quality products in a daily production cycle. The strength of the foam concrete is 1023 degrees per hour, and the daily strength is $1.6 \mathrm{MPa}$ or $55 \%$ of R28, while at the age of 28 days the strength of helio-thermobonded foam concrete is higher than that hardened under normal conditions by $51 \%$. Integrated helio-thermal processing of foam concrete in helioforms under helio cover provides high quality of products due to a combination of soft heat treatment and exothermic conditions of cement. ${ }^{24-30}$ The results of the performed studies are implemented at the plants on the production of conventional concrete, polystyrene concrete blocks of JSC "Kurylys" in Kyzylorda, LLP of the DPE of Aktau at the stage of heat treatment-solar energy. The results of the research have been tested by LLP "Construction and transport company", negotiations are being held regarding the introduction of "Almaty bridge construction plant" LLP (ABCP) (Figure 9). It should be emphasized that solar technology is highly environmentally friendly and safe. The efficiency of solar technology can be significantly enhanced by the use of new fast-hardening binders and chemical additives that have already appeared on the market and give more intensive hardening of concrete. Technical and economic calculations show that the use of solar technology saves a lot of traditional energy resources - steam or electricity and, ultimately, fuel costs. ${ }^{31-32}$

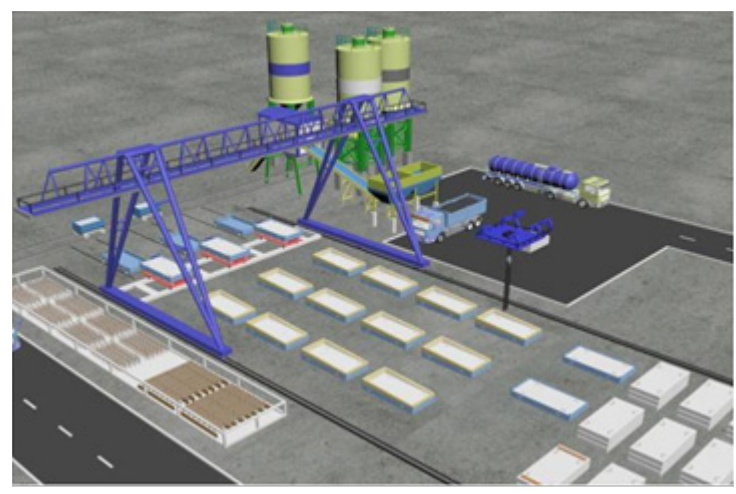

Figure 7 Diagram of open solar site of manufacturing various concrete products.

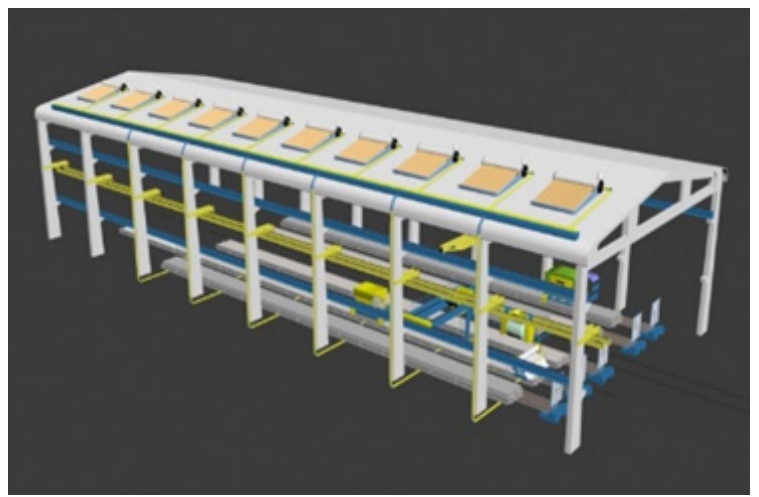

Figure 8 Diagram of manufacturing various concrete products in a closed workshop with heat treatment solar energy.

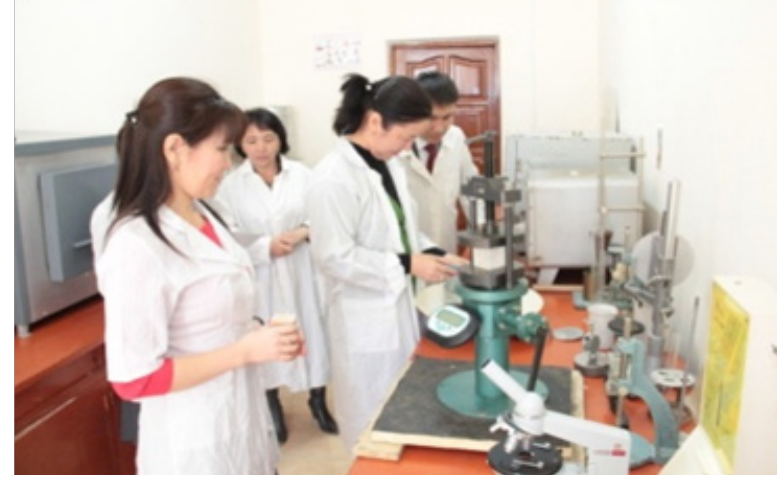

Figure 9 Doctoral students of the university conduct experimental research.

As it is known, $1 \mathrm{~kg}$ of fuel equivalent allows to get 7000 kilocalories of heat, $1 \mathrm{~kg}$ of steam allows you to get about $600 \mathrm{kcal}$., $1 \mathrm{~m}^{3}$ of gas when burned gives $8500 \mathrm{kcal}$. In the precast concrete industry, steam is mainly used for heat treatment of molded products, which is spent from 400 to $1200 \mathrm{~kg}$ per $1 \mathrm{~m}^{3}$ of reinforced concrete. Even if at an average cost of $500 \mathrm{~kg}$ steam for heating $1 \mathrm{~m}^{3}$ of reinforced concrete products, $300.000 \mathrm{kcal}$ of heat is released that corresponds to the cost of gas fuel over $35 \mathrm{~m}^{3}$ of gas for heating of $1 \mathrm{~m}^{3}$ of products. In the Republic of Kazakhstan, the output of precast reinforced concrete in 2012 was about 4765.49 thousand $\mathrm{m}^{3}$. If according to solar technology annually in the warm period of the year $200,000 \mathrm{~m}^{3}$ of precast reinforced concrete products is produced, it will be possible to save 7 million $\mathrm{m}^{3}$ of fuel in terms of gas. If in the cold months of the year the combined solar technology produces $100.000 \mathrm{~m}^{3}$ of products per year, compared to the steam heating the fuel economy may make up another 1.7 million $\mathrm{m} 3$ of gas (it is assumed that with the combined method the fuel consumption in terms of gas will be 17 $\mathrm{m}^{3}$ ). Thus, as a whole, using helium heating of concrete, the saving of fuel equivalent in terms of gas will make up 8.7 million $\mathrm{m} 3$ compared to the traditional type of heat treatment. ${ }^{33,34}$

Technologies developed by scientists of the university are in demand by a number of industrial enterprises of Kazakhstan. The results of the research and practical results of using highly effective innovative energy- and resource-saving technologies made by the authors from Kyzylordastate university, were published in more than 100 articles and protected by 14 copyright certificates and patents, there has been developed a number of recommendations for practical use, as well as textbooks and teaching aids for universities. The results obtained are very encouraging and there are wide prospects for using solar energy in other areas of the economy and industrial production. Nowadays, the country starts implementing a new development strategy "Kazakhstan-2050", its main goal is to become one of the 30 most developed countries in the world by 2050. A new course of development should lead to the formation of a competitive and knowledge-based model of the economy in Kazakhstan. With the adoption "Strategy" Kazakhstan 2050" and the Concept of transition to a"green"economy by Kazakhstan, the country has chosen a fundamentally new way of society development. According to the Concept, the direction of the state policy to reduce the impact on the environment, resource saving and the achievement of a high level of the quality of life of the population will play a key role. On the whole, the university sees the formula for the development of science in the new decade in the scientific providing high technologies in the development of economic sectors, by introducing its own and borrowing technologies to create the scientific foundations of 
technological structures that ensure the sustainable development of Kazakhstan in future.

\section{Acknowledgments}

None.

\section{Funding}

None.

\section{Conflicts of interest}

None.

\section{References}

1. GussevBV, Krylov BA, Bissenov KA, et al. Ways of reducing greenhouse gases in the production of cements and concretes in the Republic of Kazakhstan. Bulletin of the Korkyt Ata KUS. 2015;2:16-23.

2. Aruova LB, Dauzhanov NT. Innovative technologies of using solar energy in concrete technology in the Republic of Kazakhstan. 9 All-Russian scientific-practical and educational-methodical conference "Fundamental sciences in modern construction". Moscow: News letter of MGSU; 2012.

3. Aruova LB. Solar thermal treatment of reinforced concrete products using film-forming compounds. Concrete and reinforced concrete. 1994;4:23.

4. Aruova LB. The nature of the formation of temperature fields during the solar thermal treatment of concrete. Moscow: Concrete and reinforced concrete; $1996.6 \mathrm{p}$

5. Krylov BA, Aruova LB. Combined method of using solar technology on sites. Moscow: Concrete and reinforced concrete; 1996. 12 p.

6. Aruova LB, Dauzhanov NT, Krylov BA. Heliosites for the production of foam concrete products. RF News letter MSSU. 2014;4:79-87.

7. Aruova LB, Dauzhanov NT, Krylov BA. Ways to improve the competitiveness of foam concrete in modern conditions and the prospects for its use in construction. Journal of industrial civil engineering. 2014;4:15-25.

8. Dauzhanov NT, Krylov BA, Aruova LB. Technology of solar thermal treatment of foam concrete products at sites. Bulletin of the Saratov state university. 2014;1(74):35-39.

9. Aruova LB. Use of solar energy for solar thermal treatment of concrete in the Republic of Kazakhstan. International building forum "Concrete, cement, dry mixtures" November Expocenter in Moscow. Journal of Alit inform of RF. 2012;26-28.

10. Krylov BA, Bissenov KA, Aruova LB, et al. The technology of production of precast concrete by using solar energy in Kazakhstan. News letter of the Korkyt Ata KSU. 2016;2:39-49.

11. Bissenov KA, Aruova LB, Uderbayev SS, et al. Combined heliochamber for thermal processing of concrete products. Kazakhstan: The preliminary patent №10951; 2001.

12. Bissenov KA, Aruova LB, Abdibattayeva MM. Ac 35812 Method of heat treatment of concrete products. 2003.

13. Aruova LB, Dauzhanov NT. Innovative patent. Method of heat treatment of concrete products. Kazpatent: Kazakhstan; 2010.

14. Bissenov KA, Aruova LB, Abdibattayeva MM. A.c. 32667 Method of heat treatment of concrete products. Declaredon; 2000.

15. Aruova LB, Dauzhanov NT. Innovative patent. Heliosystem with an intermediate coolant for heat treatment of concrete products. Kazakhstan: Kazpatent Registered state registration; 2012.

16. Aruova LB, Dauzhanov NT. Innovative patent. "Method of heat treatment of polystyrene concrete". Innovative patent. 2010.
17. Aruova LB, Dauzhanov NT. Innovative patent. Method of heat treatment of arbolitic building products. 2012.

18. Aruova LB, Dauzhanov NT, Bissenov KA, et al. Patent "Heliochamber for heat treatment of concrete products”. Kazakhstan: Kazpatent; 2016. $31 \mathrm{p}$.

19. Aruova LB, Dauzhanov NT, Bissenov KA, et al. International patent №WO2015126231-A1. Installation for thermally treating concrete products has helio-chamber that is provided with insulating walls having securing elements and transparent top and power supply that is capable of using solar energy and electric energy. Web of Science. 2015.

20. Aruova LB, Dauzhanov NT. Process parameters of production of nonautoclaved aerated concrete on the basis of complex use of ash and gypsum-containing wastes. Mediterranean Journal of Social Sciences. 2014;5(23).

21. Aruova LB, Dauzhanov NT. Solar technology during manufacturing the reinforced concrete products in the Republic of Kazakhstan. Kazakhstan: Moscow State University of civil engineering (National research university) (MGSU); 2012.

22. Aruova LB, Utkelbayeva AO. Innovative technologies using alternative energy sources in construction. Collection of the main reports of the international forum "The First Nazarbayev Readings. New Kazakhstan in the New World” 360. 2012.

23. Combined solar thermal treatment of concrete. Almaty Science. 2004; 143 p.

24. Aruova LB, Dauzhanov NT. Innovative patent. "Method of heat treatment of foam concrete products". 2012.

25. Dauzhanov NT, Krylov BA, Aruova LB. Heliosites for the production of foam concrete products. News letter of RFPФ. 2014;4: 79-87.

26. Krylov BA, Dauzhanov NT, Aruova LB. Ways to increase the competitiveness of foam concrete in modern conditions and the prospects for its use in construction. Journal of RF Industrial civil construction. 2014;4:15-25.

27. Krylov BA, Dauzhanov NT, Aruova LB. Technology of solar heat treatment of foam concrete products at sites. Bulletin of the Saratov state university. 2014;1(74):35-39.

28. Krylov BA, Dauzhanov NT. Low-energy technology for heat treatment of foam concrete products on sites using solar energy. RF Bulletin of $M G S U$. 2014;3:149-157.

29. Aruova LB, Krylov BA, Dauzhanov NT. Increase of competitiveness of foam concrete and prospects of its application in construction. Industrial and civil construction of the Russian Federation. 2015;19-23.

30. Bissenov KA, Aruova LB, Abdibattayeva MM. Ac 30968 Combined heliochamber for thermal processing of concrete products. 2000.

31. Bissenov KA, Aruova LB, Abdibattayeva MM. Ac 35321 Combined solar-electric chamber for heat treatment of concrete products. 2003.

32. Aruova LB, Dauzhanov NT. Process parameters of production of nonautoclaved aerated concrete on the basis of complex use of ash and gypsum-containing wastes. Mediterranean Journal of Social Sciences 5. 2014.

33. Bissenov KA, Aruova LB, Arynova ZS, et al. Technology of using solar energy in the production of various types of concrete products and structures in the Republic of Kazakhstan. III 3nd All Russian (International) Conference on Concrete and Reinforced Concrete. 2014.

34. Bissenov KA, Aruova LB, Utkelbayeva AO, et al. The Technology of production of precast concrete by using solar energy in Kazakhstan. International Conference on "Multidisciplinary innovation in business engineering science technology" (MI-BEST-2015). 2015;26-27. 